\title{
Vulnerabilidade dos usuários de crack à infecção pelo vírus da imunodeficiência humana
}

Recebido em: 20/03/2013

Aprovado em: 16/05/2014
Telma Maria Evangelista de Araújo' Anderson da Silva Sousa ${ }^{2}$ Thiego Ramon Soares ${ }^{3}$ Rafael Alves Clementino ${ }^{4}$

Laís Carvalho de Sá

Sângela Medeiros de Lima ${ }^{6}$

Resumo: Objetivou-se investigar a vulnerabilidade dos usuários de crack cadastrados nos Centro de Atenção Psicossocial Álcool e Drogas (CAPSad) do Piauí, com relação à infecção pelo Human Imunodeficiency Vírus (HIV). Trata-se de um inquérito epidemiológico, realizado nos CAPSad do Piauí, com 343 usuários. Predominaram o sexo masculino, com média de idade de 29,2 anos. Os fatores de riscos predominantes foram múltiplos parceiros sexuais, uso de álcool e drogas antes do sexo, história de prisão e tatuagem. Conclui-se que os usuários de crack constituem um grupo com a susceptibilidade aumentada à infecção pelo vírus HIV, devido comportamentos de risco por eles assumidos.

Descritores: HIV. Cocaína crack. Vulnerabilidade.

Vulnerability of crack users to the infection by human imunodeficiency virus

Abstract: The aim of this work was to investigate the vulnerability of crack users enrolled in Psychosocial Care Center Alcohol and Drugs (CAPSad) Piauí, with respect to infection Imunodeficiency Human Virus (HIV). This is a survey carried out in CAPSad the state of Piaui, with 343 users. A predominance of male sex with mean age of 29.2 years. The risk factors were predominant multiple sexual partners, use of alcohol and drugs before sex, and history of prison tattooing. It is concluded that crack users are a group with increased susceptibility to HIV infection, risk behaviors because they assumed.

Descriptors: HIV. Crack cocaine. Vulnerability.

\section{Vulnerabilidad de los consumidores de crack a la infección por el virus human imunodeficiency}

Resumen: El objetivo era investigar la vulnerabilidad de los consumidores de crack inscrito en Alcohol Centro de Atención Psicosocial y Drogas (CAPSad) Piauí, con respecto a la infección del Virus Imunodeficiency Humana (VIH). Se trata de un estudio llevado a cabo en CAPSad el estado de Piauí, con 343 usuarios. Se identificó predominio de hombres del sexo masculino, con una edad media de 29,2 años. Los factores de riesgo predominantes fueron múltiples parejas sexuales, uso de alcohol y drogas antes de tener sexo, y la historia de los tatuajes prisión. Se concluye que los usuarios de crack son un grupo con una mayor susceptibilidad a la infección por VIH, las conductas de riesgo, ya que se supone.

Descriptores: VIH. Cocaína crack. Vulnerabilidad.

\section{INTRODUÇÃO}

$\mathrm{O}$ consumo de crack vem se constituindo um dos problemas mais discutido e preocupante no contexto da saúde pública, devido aos danos sociais, econômicos e de saúde pública. Dentre os usuários de drogas, destaca-se o usuário de crack uma vez que apresentam maior tendência a desenvolverem comportamentos de risco devido ao poder dependência que a droga causa no Sistema Nervoso Central ${ }^{(1-3)}$.

Os usuários de crack estão, frequentemente, envolvidos em atividades violentas, ilícitas como roubo, tráfico e assaltos, e atividades sexuais de risco para adquirir dinheiro ou drogas. Com relação à prostituição, este comportamento é utilizado para a troca de sexo por dinheiro ou droga, assumindo comportamentos de risco para a infecção pelo Human Imunodeficiency Vírus (HIV), já que esta prática é realizada com maior frequência durante a fase de fissura, pois o desejo pela droga tem prioridade sobre a proteção durante as práticas sexuais ${ }^{(4)}$.

$\mathrm{O}$ uso prolongado do crack está fortemente correlacionado com a infecção ou re-infecção pelo vírus do HIV. De acordo com Dias, Araújo e Laranjeira ${ }^{(5)}$, "o uso do crack não é apenas um fator de risco para o HIV, mas também funciona como um catalisador dos agravamentos dessa condição entre os soropositivos", aumentando o risco para as outras doenças sexualmente transmissíveis (DSTs), como a hepatite $B$, sífilis e gonorreia.

No estudo ${ }^{(3)}$ realizado em Porto Alegre no período de 1995 a 1999 demonstrou que a taxa de mortalidade entre os usuários de crack é cerca de sete vezes maior que na população geral. A infecção pelo HIV na população do estudo foi responsável por $26,1 \%$ das mortes.

Sobre a epidemiologia do HIV no Piauí, verificou-se que $82,55 \%$ foram transmitidos por meio do sexo e aproximadamente em $3 \%$ a transmissão foi sanguínea entre usuários de drogas injetáveis. Não existem dados oficiais no Estado, em relação à situação do HIV em usuários de drogas não injetáveis( ${ }^{(6)}$.

Face às considerações levantadas e a gravidade da infecção pelo vírus HIV, somada a escassez de estudos na nossa realidade piauiense, que associem o uso de crack com o comportamento de risco para adquirir o HIV, esse estudo

'Doutora pela Universidade Federal do Rio de Janeiro/EEAN. Professora da Graduação edo Programa de Mestrado em Enfermagem da UFPI. Diretora de Vigilância e Atenção à Saúde do Estado do Piauí. E-mail: telmaevangelista@gmail.com

${ }^{2}$ Graduado em Enfermagem pela Faculdade de Saúde, Ciências Humanas e Tecnológicas do Piauí (NOVAFAPI). E-mail: gaucho.23@hotmail.com

${ }^{3}$ Graduado em Enfermagem pela Faculdade de Saúde, Ciências Humanas e Tecnológicas do Piauí (NOVAFAPI). E-mail: thiegoramonth@hotmail.com

${ }^{4}$ Graduado em Enfermagem pela Faculdade de Saúde, Ciências Humanas e Tecnológicas do Piauí (NOVAFAPI). E-mail: rafael.mp3@hotmail.com

${ }^{5}$ Mestre em Enfermagem pela Universidade Federal do Piauí. Teresina, Piauí, Brasil. Email: laiscdesa@gmail.com

${ }^{6}$ Mestranda do Programa de Pós-graduação Mestrado em Enfermagem da Universidade Federal do Piauí. Teresina, Piauí, Brasil. Docente da Faculdade de Educação São Francisco (FAESF), Pedreiras, Maranhão. Email: sangelamedeiros84@gmail.com 
tem como objetivo investigar a vulnerabilidade dos usuários de crack cadastrados nos Centro de Atenção Psicossocial Álcool e Drogas (CAPS ad) do Piauí com relação à infecção pelo vírus HIV.

\section{METODOLOGIA}

Realizou-se um estudo seccional por meio de um inquérito epidemiológico, desenvolvidos nos CAPS ad do Piauí, nos municípios de Teresina, Parnaíba, Picos e Piripiri.

Para o cálculo amostral levou-se em consideração um erro tolerável de 5\%, com nível de significância de 95\%, obtendo-se 361 participantes. Foram excluídos do estudo todos aqueles que não consentiram em participar e os que não tiveram em condições de responder as questões de interesse da pesquisa.

A coleta dos dados foi realizada no período de novembro de 2011 a maio de 2012, através de uma entrevistas com a aplicação de formulário pré-testado, contendo perguntas fechadas e algumas semi-abertas. As informações obtidas foram armazenadas em banco de dados e em seguida submetidos à análise estatística utilizando-se o aplicativo Statistical Package for the Social Science (SPSS, versão 18.0).

O projeto de pesquisa foi aprovado pelo Comitê de Ética em Pesquisa da Universidade Federal do Piauí (UFPI) (CAAE: 0091.0.045.000-11). Os entrevistados assinaram o Termo de Consentimento Livre e Esclarecido.

\section{RESULTADOS}

Entre os 361 usuários de crack selecionados, 343 participaram do estudo, com perda de 4,98\%.

Segundo a Tabela 1, 55,1\% da amostra estavam compreendidos na faixa etária de 19 a 30 anos; 84,8\% eram homens; $67,9 \%$ declaram-se solteiros; $76,3 \%$ possuíam escolaridade compatível com o Ensino Fundamental e 46,2\% tinham renda familiar menos de 1 salário mínimo.

Tabela 1: Caracterização Sociodemográfica e Econômica dos Usuários de Crack do estudo. Teresina/PI - 2013 ( $n=243$ ).

\begin{tabular}{|c|c|c|}
\hline $\begin{array}{l}\text { Variáveis relacionadas } \\
\text { ao gerenciamento dos } \\
\text { resíduos }(n=19)\end{array}$ & $\mathbf{n}$ & $\%$ \\
\hline Variáveis & $\mathrm{n}$ & $\%$ \\
\hline \multicolumn{3}{|l|}{ Faixa etária } \\
\hline 19 a 30 & 189 & 55,1 \\
\hline 31 a 60 & 126 & 36,7 \\
\hline Até 18 anos & 27 & 7,9 \\
\hline 61 e mais & 01 & 0,3 \\
\hline \multicolumn{3}{|c|}{$\begin{array}{l}\text { Média }=29,2 ; \text { Desvio padrão = 8,6; Min. e Máx = } 39 \text { e } 65 ; 1 . C 95 \% \text { : } \\
28,2-30,1\end{array}$} \\
\hline \multicolumn{3}{|l|}{ Sexo } \\
\hline Masculino & 291 & 84,8 \\
\hline Feminino & 52 & 15,2 \\
\hline \multicolumn{3}{|l|}{ Situação conjugal } \\
\hline Solteiro/Separado & 233 & 67,9 \\
\hline Casado/unido & 110 & 32,1 \\
\hline \multicolumn{3}{|l|}{ Escolaridade } \\
\hline Ensino Fundamental & 262 & 76,3 \\
\hline Ensino Médio & 50 & 14,5 \\
\hline
\end{tabular}

\begin{tabular}{|c|c|c|}
\hline Ensino Superior incompleto & 21 & 6,1 \\
\hline Sem escolaridade & 08 & 2,3 \\
\hline Superior completo & 03 & 0,8 \\
\hline \multicolumn{3}{|l|}{ Faixa de renda pessoal (SM) } \\
\hline Até 1 & 78 & 46,2 \\
\hline$>1$ a 2 & 49 & 29,0 \\
\hline$>2$ a 3 & 29 & 17,2 \\
\hline Mais que 3 & 13 & 7,7 \\
\hline \multirow{3}{*}{\multicolumn{3}{|c|}{$\begin{array}{l}\text { Média = 945; Desvio padrão = 621,5; Mín. e Máx. = } 30 \text { e 3.000; I.C 95\%: } \\
850-1039 \\
\text { A Tabela } 2 \text { evidencia que o sexo vaginal foi o tipo mais } \\
\text { frequente }(95,3 \%) ; 53,4 \% \text { tiveram mais de um parceiro } \\
\text { sexual nos últimos seis meses; } 54,0 \% \text { usam frequentemente } \\
\text { o preservativo; } 62,1 \% \text { consomem bebida alcoólica antes } \\
\text { das relações sexuais; } 59,1 \% \text { usam drogas antes das relações } \\
\text { sexuais; } 8,5 \% \text { já tiveram atividade sexual com usuários de } \\
\text { droga injetável e } 31,2 \% \text { apresentaram DSTs. Com relação } \\
\text { aos outros comportamentos de risco que não envolvem } \\
\text { prática sexuais, } 8,8 \% \text { realizaram transfusão sanguínea, } \\
65,0 \% \text { foram detidos em prisões; } 58,9 \% \text { possuem tatuagem } \\
\text { e } 11,4 \% \text { usam piercing. } \\
\text { Tabela } 2 \text { - Fatores preditores para a infecção pelo HIV na } \\
\text { amostra estudada. Teresina/PI - } 2013 \text { ( } n=343 \text { ). }\end{array}$}} \\
\hline & & \\
\hline & & \\
\hline Fatores de risco & $\mathbf{n}$ & $\%$ \\
\hline \multicolumn{3}{|c|}{ Tipo de sexo mais frequente $(n=342)$} \\
\hline Vaginal & 326 & 95,3 \\
\hline Anal & 06 & 1,8 \\
\hline Oral & 10 & 2,9 \\
\hline \multicolumn{3}{|l|}{ Parceiros sexuais } \\
\hline Único & 136 & 46,6 \\
\hline Mais de um & 156 & 53,4 \\
\hline \multicolumn{3}{|c|}{ Uso de camisinha nas relações sexuais $(n=342)$} \\
\hline Frequentemente & 169 & 54,0 \\
\hline Às vezes & 85 & 24,3 \\
\hline Raramente & 34 & 7,5 \\
\hline Nunca & 54 & 14,2 \\
\hline \multicolumn{3}{|c|}{ Uso de bebidas antes das relações $(n=342)$} \\
\hline Sim & 207 & 62,1 \\
\hline Não & 125 & 37,9 \\
\hline \multicolumn{3}{|c|}{ Uso de drogas antes das relações ( $n=342)$} \\
\hline Sim & 202 & 59,1 \\
\hline Não & 140 & 40,9 \\
\hline \multicolumn{3}{|c|}{ Já teve relação sexual com usuário de droga injetável } \\
\hline Não & 313 & 91,5 \\
\hline Sim & 29 & 8,5 \\
\hline \multicolumn{3}{|l|}{ Teve DST } \\
\hline Sim & 107 & 31,2 \\
\hline Não & 236 & 68,8 \\
\hline \multicolumn{3}{|c|}{ Realizou transfusão de sangue } \\
\hline Sim & 30 & 8,8 \\
\hline Não & 312 & 91,2 \\
\hline Episódio prisional & & \\
\hline
\end{tabular}




$\begin{array}{|lcc|}\text { Sim } & 223 & 65,0 \\ \text { Não } & 120 & 35,0 \\ \text { Tem tatuagem } & 202 & 58,9 \\ \text { Sim } & 141 & 41,1 \\ \text { Não } & & \\ \text { Usa piercing } & 39 & 11,4 \\ \text { Sim } & 304 & 88,6\end{array}$

Segundo a tabela 3, ao cruzar os fatores considerados preditores da vulnerabilidade para o HIV com a escolaridade na população do estudo, apenas o fato de já ter sido preso teve associação estatisticamente significativa $(p<0,01)$.

Tabela 3 - Associação dos fatores de risco para o HIV com a escolaridade da amostra estudada. Teresina/PI - $2013(n=343)$.

\begin{tabular}{|c|c|c|c|}
\hline \multicolumn{4}{|c|}{ Escolaridade } \\
\hline & $\begin{array}{c}\text { Ensino } \\
\text { fundamental } \\
\text { a médio } \\
\text { incompleto }\end{array}$ & $\begin{array}{l}\text { Ensino médio } \\
\text { completo a } \\
\text { superior }\end{array}$ & \multirow[t]{2}{*}{$\stackrel{p}{\mathbf{p}}$} \\
\hline Variáveis & $n(\%)$ & $n(\%)$ & \\
\hline Usa camisinha & 06 & 1,8 & \multirow{5}{*}{0,72} \\
\hline Frequentemente & $124(77,0)$ & $37(23,0)$ & \\
\hline Às vezes & $63(84,0)$ & $12(16,0)$ & \\
\hline Raramente & $15(78,9)$ & $04(21,1)$ & \\
\hline Nunca & $32(80,0)$ & $08(20,0)$ & \\
\hline \multicolumn{4}{|c|}{ Uso de bebidas antes das relações } \\
\hline Sim & $97(77,6)$ & $28(22,4)$ & \multirow[t]{3}{*}{0,99} \\
\hline Não & $95(77,9)$ & $27(22,1)$ & \\
\hline Às vezes & $55(77,5)$ & $16(22,5)$ & \\
\hline \multicolumn{4}{|c|}{ Uso de drogas antes das relações } \\
\hline Sim & $86(72,3)$ & $33(27,7)$ & \multirow[t]{3}{*}{0,17} \\
\hline Não & $106(79,1)$ & $28(20,9)$ & \\
\hline Às vezes & $64(83,1)$ & $13(16,9)$ & \\
\hline \multicolumn{4}{|c|}{ Uso de drogas antes das relações $(n=342)$} \\
\hline Sim & 202 & 59,1 & \\
\hline Não & 140 & 40,9 & \\
\hline \multicolumn{4}{|l|}{ Já foi preso } \\
\hline Sim & $179(84,4)$ & $33(15,6)$ & \multirow[t]{2}{*}{$<0,01$} \\
\hline Não & $78(65,5)$ & $41(34,5)$ & \\
\hline
\end{tabular}

\section{DISCUSSÃO}

No presente estudo observou-se que o perfil dos usuários de crack foi predominantemente do sexo masculino, baixa renda, com menos de um salário mínimo, com idade entre 19 e 30 anos e baixa escolaridade. No VI Levantamento Nacional sobre o Consumo de Drogas Psicotrópicas mostra que a baixa escolaridade se torna um dos fatores que ajuda na disseminação da droga, já que a maioria não vai além do ensino fundamental e dificilmente voltarão aos estudos, pois, as drogas tiram o estímulo para atividades dessa natureza(7).

Apesar de uma pequena maioria da amostra estudada ter relato o uso do preservativo, a literatura aponta que seu uso é pouco frequente entre os usuários de crack, pois sugerem um possível efeito modelador das substancias psicoativas sobre as práticas sexuais(8). Acresce-se a isto que o uso oral traz sérios riscos à saúde, especialmente relacionado à transmissão do HIV e hepatite $B$, considerando que as fissuras e lacerações na cavidade oral dos usuários de crack são frequentes, o que funciona como porta de entrada ou de saída dos respectivos vírus(9). Outro fator de risco observado na maior parcela da população estudada foi a prática sexual com múltiplos parceiros, aumentando os riscos para adquirirem HIV. Esse comportamento sexual assegura um dos fatores de risco mais observados entre os usuários de droga ${ }^{(10)}$.

Notou-se que uma expressiva parcela dos usuários de crack fazia uso de álcool e drogas antes da relação sexual. Existem evidências sustentadas que afirmam a perda do desejo sexual dos usuários de droga, quando estão sob efeito do $\mathrm{crack}^{(10)}$. O uso de álcool funciona como umas forma paliativa dos efeitos negativos do crack $^{(11)}$.

A fissura gera uma sensação de urgência pelo uso do crack entre os seus usuários(11). Desse modo eles esgotam seus recursos financeiros vendo-se obrigados a realizar atividades fora do mercado legal do trabalho comprometendo sua liberdade e integridade física. Tal informação vem ao encontro dessa pesquisa uma vez que $65 \%$ dos entrevistados, já passaram pela experiência de terem sido presos.

Na presente pesquisa verificou-se que as DSTs foram frequentes entre os usuários de crack, o que os tornam mais vulneráveis ao HIV. Em 1985 o Programa Nacional de DST/ Aids foi criado com o propósito de direcionar estratégias relacionadas à área de saúde sexual e reprodutiva no Brasil, especialmente com relação à infecção pelo HIV. No Brasil, estima-se a prevalência do HIV em 600 mil pessoas e 30 milhões para os portadores de DST. Nesse cenário, os elevados índices de DST e sua relação com o HIV justificam a inclusão da atenção às DST/Aids nas ações de saúde reprodutiva ${ }^{(12)}$.

Outro fator de risco observado na população deste estudo diz respeito ao uso de tatuagens e piercings. Tal risco se dá em função da inobservância das medidas de biossegurança, por ocasião dos procedimentos de aplicação/colocação dos mesmos, o que pode levar dentre outras, à infecção pelo vírus HIV.

A variável detenção prisional foi estatisticamente associada ao HIV, devido ao efeito cumulativo de exposição para risco de infecção. Devido ao acesso limitado aos insumos, práticas de risco que são realizadas, como a aplicação de tatuagens e piercings não esterilizados, bem como práticas sexuais homossexuais, agressões sexuais e compartilhamento da parafernália de drogas não injetáveis e injetáveis (WHO, 2012a).

\section{CONCLUSÃO}

Conclui-se que os usuários de crack constituem um grupo com a susceptibilidade aumentada à infecção pelo vírus HIV, assim como para outras DSTs, o que pode ser evidenciado pelos comportamentos de risco assumidos pela situação de vulnerabilidade social dos mesmos.

Foram evidenciados muitos aspectos importantes para o aumento da vulnerabilidade deste grupo, pois em sua maioria são jovens do sexo masculino, com baixa renda familiar e baixo nível de escolaridade. Além disso, observou-se que as estratégias de consumo da droga contribuem significativamente para o aumento da vulnerabilidade deste grupo, destacando-se o uso em cachimbos artesanais 
de latas de alumínios, pedaços de PVC e outros materiais com capacidade lacerante. Soma-se a isto, o uso do crack associado a drogas injetáveis.

Destaca-se como ponto de relevante importância no aumento da vulnerabilidade à infecção pelo HIV deste grupo, o comportamento sexual de risco assumido por eles, uma vez que aproximadamente $50 \%$ usam preservativo eventualmente ou nunca usaram em suas relações sexuais. Além disso, praticam sexo oral sem preservativo, têm múltiplos parceiros sexuais e praticam atividades sexuais sob efeito do álcool e outras drogas. Outro achado importante deste estudo, diz respeito ao conhecimento sobre o HIV e suas formas de transmissão.
Observou-se que, não obstante a expressiva maioria conheça os principais modos de transmissão, e sendo a televisão e os serviços de saúde as maiores fontes de informação, há uma dissonância significativa entre conhecimento e prática, sugerindo a presença de outros fatores intervenientes, que este estudo não deu conta de investigar.

Ressalta-se a relevância ímpar da participação da enfermagem no desenvolvimento, assim como na execução das políticas direcionadas para esta população, dando ênfase nas atividades educativas e de redução de danos das práticas por eles realizadas.

\section{Referências}

1. Guimarães CF, Santos DVV, Freitas RC, Araujo RB. Perfil do usuário de crack e fatores relacionados à criminalidade em unidade de internação para desintoxicação no Hospital Psiquiátrico São Pedro de Porto Alegre (RS). Rev. psiquiatr. Rio Gd. Sul. 2008; 30(2): 101-108.

2. Azevedo RCS, Botega NJ, Guimarães LAM. Crack users, sexual behavior and risk of HIV infection. Rev. bras. Psiquiatr. 2007; 29(1):26-3.

3. Ribeiro M, Dunn J, Sesso R, Dias AC, Laranjeira R. Causes of death among crack cocaine users. Revista Brasileira Psiquiatria. 2006; 28(3):196-202.

4. Chaves TV, Sanchez ZM, Ribeiro LA, Nappo SA. Fissura por crack: comportamentos e estratégias de controle de usuários e ex-usuários. Rev. Saúde Pública. 2011; 45(6): 1168-1175.

5. Dias AC, Araújo MR, Laranjeira R. Evolução do consumo de crack em coorte com histórico de tratamento. Rev. Saúde Pública. 2011; 45(5): 938-48.

6. Piauí (BR). Secretaria de Estado da Saúde. Rede de Saúde Mental do Estado do Piauí. Relatório de Atividades. Teresina: 2011.
7. Centro Brasileiro de Informação sobre Drogas Psicotrópicas. VI Levantamento Nacional sobre o Consumo de Drogas Psicotrópicas entre Estudantes do Ensino Fundamental e Médio das Redes Pública e Privada de ensino nas 27 capitais brasileiras. São Paulo: CEBRID, 2010.

8. Bastos Fl, Cunha CB, Bertoni N. Uso de Substâncias Psicoativas e métodos contraceptivos pela população urbana brasileira, 2005. Rev. de Saúde Pública. 2008; 42(1): 118-26.

9. Ministério da Saúde (BR). Secretaria de Vigilância em Saúde. Recomendações para profilaxia da transmissão vertical do HIV e terapia antirretroviral em gestantes. Brasília, 2010.

10. Duailibi LB. Revisão Sistemática: Perfil dos usuários de cocaína e crack no Brasil [tese]. São Paulo (SP): Universidade Federal de São Paulo; 2010.

11. Oliveira LG, Nappo SA. Crack na cidade de São Paulo: acessibilidade, estratégias de mercado e formas de uso. Rev. psiquiatr. clín. 2008; 35(6): 212-18.

12. Aquino PS, Ximenes LB, Pinheiro AKB. Políticas públicas de saúde voltadas à atenção à prostituta: breve resgate histórico. Enfermagem em Foco. 2010; 1(1):18-22.

13. World Health Organization (WHO). Guidance on prevention of viral hepatitis $\mathrm{B}$ and $\mathrm{C}$ among people who inject drugs. WHO, 2012. 